\title{
Theories of Niche Construction and Optimal Foraging: weaknesses and virtues in understanding the early stages of domestication
}

Ernani Machado de Freitas Lins Neto ${ }^{1, *}$ and Ulysses Paulino de Albuquerque ${ }^{2}$

\begin{abstract}
The transition from hunter-gatherer condition to the development of agricultural practices has provided one of the greatest technological advances of humanity. In view of the importance of this phenomenon and still persistent gaps, theoretical models emerge to elucidate issues related to the beginning of the domestication of animals and plants, a crucial moment for understanding socioecological and evolutionary factors that are determinant for environmental manipulation. Two theoretical models are relevant in this discussion: theories of optimal foraging and niche construction. In this sense, this mini-review highlights the debate of these two perspectives on the beginning of domestication highlighting weaknesses and virtues of each proposal.
\end{abstract}

Keywords: Diet Breadth; Evolutionary Ethnobiology; Management; Domestication.

\footnotetext{
${ }^{1}$ Laboratório de Ecologia e Etnobiologia (LECET), Colegiado de Ecologia/Campus Senhor do Bonfim-BA, Universidade Federal do Vale do São Francisco, Senhor do Bonfim, BA, 42970-000, Brazil.

2 Laboratório de Ecologia e Evolução de Sistemas Socioecológicos (LEA), Centro de Biociências (CCB), Universidade Federal de Pernambuco, Recife, PE, 50670-901, Brazil

* Corresponding author. $]$ E-mail address: EMFLN (ernani.linsneto@univasf.edu.br), UPA (upa677@hotmail.com).
}

\section{INTRODUCTION}

The domestication of plants and animals phenomenon made possible unimaginable advances for humanity, since it allowed the control and predictability in the supply of natural resources, and with that, greater food security (Heiser 1988; Casas et al. 1997; Lins Neto et al. 2014). Consequently, technological and scientific development has arisen as an emerging property of human interactions with the ecosystem, making the environment increasingly safe and suited to the development of society. However, the question remains, what led humans to the beginning of domestication? Evidences indicate that this phenomenon does not appear to have occurred in exactly the same way, although the process itself arose almost simultaneously at different locations worldwide without an apparent connection (Casas et al. 1997; Lins Neto et al. 2014). It is believed that the need to master nature, making it predictable and adequate to the growing needs of human populations, were the main driving forces of domestication. 
However, how has this occurred in different ecological and cultural contexts?

Two theoretical models are relevant to discuss the origins of the phenomenon of domestication of plants and animals: theories of optimal foraging, more specifically the strand that deals with the diet breadth model (DBM), and the of niche construction theory (NCT). The debate over these propositions has been stirring in recent years. Recently, Zeder (2015a) emphasized that the niche-construction theory is the model that would best explain the beginning of domestication. However, Mohlenhoff et al. (2015) contrasted the ideas of Zeder (2015a) emphasizing that the niche-construction theory could not explain the first steps towards the domestication of plants and animals alone. In this sense, this mini-review introduces the debates of these two models, highlighting fragilities and virtues of each perspective in the explanations about the origin of plants and animals domestication.

\section{Diet breadth model}

When considering the beginning of domestication, three main forces are commonly cited as triggering this phenomenon: environmental changes, demographic aspects induced by use pressure and changes in social and ideological organization (Zeder 2016). For the diet breadth model (DBM) (MacArthur and Pianka 1966; Emlen 1966), the decision of the forager is based on the energy return of the hunting or gathering in relation to the energy expenditures derived from these activities, also considering the costs associated with post-gathering and posthunting handling (Hawkes and O'Connell 1992). In this sense, there are preferred resources, considering the energy balance described previously, within the list of plants and animals used for human consumption. For DBM, the search for resources with the highest energy return continues even in the face of an abundant resource, but with a low energy return, since the reward outweighs the costs of demand. Plants with small seeds and underground stored organs, for example, are positioned well below in the preferences of foraging resources, since they present low energy value and a high processing cost (Gremillion et al. 2014).

In the diet breadth model, domestication emerges as an adaptive response of a society to an imbalanced environment (Smith 2016). As a result of the latter, the exhaustion of the resource occurs, characterized by the scarcity in its availability, together with an increase in the human energy demand, resulting either from the reduction of the support capacity of the areas of collection and of the plants and animals, or in the increase of the population density (Smith 2015, 2016). In this sense, it is observed that this model is deterministic, and by excellence, unidirectional, since the environment is the defining agent of human behavior, being an exclusively one-way path (Smith 2015; Zeder 2015a). In order to test these models empirically, Smith (2015) suggests the following predictive conditions, based on the hypothetical exhaustion of a resource: population increase and evidence of climate change culminating in decreasing abundance and availability of plants or animals. When testing the above-mentioned conditions, studies performed in the eastern United States and in the Neotropics have not found that environmental imbalance or resource depletion are determining factors for the beginning of the domestication process (Smith 2016). However, in both cases, signs of human environmental manipulation in order to increase the abundance and predictability of resources 
were identified, a context advocated by niche construction theory (Smith 2016).

\section{Niche construction theory}

In contrast to the propositions of classical evolutionary theory, in which the optimal foraging theory is epistemologically supported, there is the perspective of the organism (or for the case in question, human beings) not being passive in the face of the imperatives of the environment, but to interact intensely in order to modify it in accordance with their interests (Laland et al. 2001). In this sense, the deterministic, unidirectional perspective of the diet breadth model described above is dispensed, considering the mutual influence in this "twoway" relationship (reciprocal influence) proposed by NCT.

Local environmental disturbance or imbalance does not always appear as the main triggering factor for an adaptive response of the organism, as proclaimed by the diet breadth model. NCT proponents consider that differently from what is exposed for optimal foraging theories, landscape manipulation may arise in environments with high abundance and diversity of plants and animals (Smith 2012; Smith 2016). Such conditions not only facilitate the mastery of these areas of interest, but also allow for experimentation and consequently the development of management techniques that increase productivity (Zeder 2016). Thus, people naturally moved to a sophisticated landscape management, which was improved and transmitted through ecological and cultural heritage to subsequent generations (Smith 2012; Smith 2016). According to Smith (2016), when testing NCT, the basic premise of human intervention in the environment is to modify it according to its interests, in contrast to DBM. Thus, this theory predicts that domestication may have begun under conditions of stability or increased availability of resources, disregarding their depletion and energy imbalance as process-triggering forces (Smith 2015). Therefore, to test nicheconstruction theory as a possible explanation for the beginning of domestication, Smith (2015) suggests the following environmental conditions to verify the model: abundance of resource; low population density reflected by smaller and less numerous human settlements; paleoenvironmental evidence of resource richness, which may indicate the collection by human groups of a wide spectrum of plants and animals, and human intervention signals aimed at manipulation of the environment (such as fires and clearings) (see Smith 2015).

Another aspect ignored by the diet breadth model is the traditionalism in the use of resources, as well as the transmission of this knowledge throughout the generations (Zeder 2016). The niche-construction theory, besides contemplating the latter aspects, assumes that the selection and management of the environment is revealed as a constant integration and experimentation of new resources to be included to the list of useful resources, culminating in the first steps in the direction of domestication. The process of domestication, according to Zeder (2016), perfectly exemplifies how the human capacity for creation and transmission of knowledge restructured the ecological interrelations causing evolutionary changes not only in the targeted species, but also throughout the environment.

The core of the discussion lies in the theoretical assumptions which, on the one hand, consider the environment as a determinant, limiting and modifying factor of 
human intervention on the landscape (OFT/DBM) and on the other hand deals with the relationship between people and the environment as a "two-way" path, and human intervention is decisive in the construction of a favorable environment for the development of humanity (NCT) (Smith 2016).

\section{Final considerations}

In a synthetic way, both models present virtues and limitations to explain the beginning of the process of domestication. For proponents of OFT/DBM the nicheconstruction theory is either flawed or insufficient to explain the beginning of domestication because it lacks a general theory of human behavior that is needed to explain why people construct niches (Mohlenhoff et al. 2015). According to OFT/DBM the domestication arises in the context of depletion of resources, from an imbalanced environment and with increasing human population, admitting the model of niche construction as a posteriori behavior Smith (2015). It is emphasized that the cultural perspective is of lower relevance to DBM, while for NCT, domestication does not necessarily begin in an unbalanced environment, and may arise in conditions of resource richness, culminating in domestication of plants and animals (Smith 2016; Zeder 2015b). NCT contemplates the role of acquired behavior and its transmission, highlighting the condition of cooperation and co-evolution expressed in the relation of the species targeted for domestication to the people (Zeder 2015b). These, while are transformers are also transformed (Zeder 2016), an aspect neglected by DBM.

Jones and Hurley (2017) from a literature review on the use of forage theory in zooarchaeology and archaeobotany, supports the argument that the forage and niche construction theories may be complementary approaches. Avoiding the polarization between the two proposals, Mohlenhoff et al. (2015) consider that the models are not mutually excluding, and thus, they suggest that it would be more interesting to admit that the combination of both approaches is more constructive. According to the authors, the optimal foraging theory could be the starting point, when considering the environment, determining the initial limiting conditions to create the necessary scenario for the niche construction behavior to act, therefore, in the landscape modeling. However, recent evidence shows that humans can initiate the use and management of resources in different resource abundance scenarios (Gonçalves et al. 2016; Dai et al. 2017). Gonçalves et al. (2016) show that the use of plant resources is not always directly related to their abundance. Therefore, these findings suggest that the initial conditions of the environment may be diverse.

Mohlenhoff and Codding (2017) reinforced the thesis that the alliance between the two perspectives, OFT / DBM and NCT, is the most appropriate way, since cost-benefit is the driving force in the evolutionary process, especially considering the theories of human behavioral ecology (HBE). According to the authors, the construction of niche as an explanatory model of human evolution is a recent application, developed mainly in the discussions focused on the process of domestication. Thus, it is necessary to test the NCT model in the most varied circumstances, as done by Albuquerque et al. (2017) in the Araripe National Forest, directing attention mainly to elucidation of the initial factors that influenced the 
transformation of the environment by people (Mohlenhoff and Codding 2017).

It is concluded that domestication is a coevolutionary phenomenon that enables a more detailed understanding of the role of acquired knowledge and its inheritance as modeling and maintainers of the landscape. However, it is necessary to intensify the studies about the two theoretical models, OFT/DBM and NCT, applying them in the most varied ecosystemic and cultural conditions, in order to elucidate the questions related to the beginning of the domestication process.

\section{REFERENCES}

Albuquerque UP, Gonçalves PHS, Ferreira Júnior WSF, Chaves LS, Oliveira RCS, Silva TLL, Santos GC, Araújo EL (2017) Humans as niche constructors: Revisiting the concept of chronic anthropogenic disturbances in ecology. Perspectives in Ecology and Conservation 16(1):1-11.

Casas A, Caballero J, Mapes C, Zárate S (1997) Manejo de la vegetación, domesticación de plantas y origen de la agricultura em mesoamérica. Boletín de la Sociedad Botánica del México 61: 31-47.

Dai X, Zhang W, Xu J, Duffy KJ, Guo Q (2017) Global pattern of plant utilization across different organisms: Does plant apparency or plant phylogeny matter? Ecology and Evolution 7:2535-2545.

Emlen $\mathrm{J}(1966)$ The role of time and energy in food preference. American Naturalist 100:611-617

Gonçalves PHS, Albuquerque UP, Medeiros PM (2016) The most commonly available woody plant species are the most useful for human populations: a meta-analysis. Ecology and Application 26(7):2238-2253.

Gremillion KJ, Barton L, Piperno D (2014) Particularism and the retreat from theory in the archaeology of agricultural origins. Proceedings of the National Academy of Sciences of the United States of America 111(17):6171-6177.
Hawkes K, O'Connell JF (1992) On optimal foraging models and subsistence transitions. Current Anthropology 33:63-65.

Heiser CB (1988) Aspects of unconscious selection and evolution of domesticated plants. Euphytica 37: 77-81.

Jones EL, Hurley DA (2017) Beyond Depression? A Review of the Optimal Foraging Theory Literature in Zooarchaeology and Archaeobotany. Ethnobiology Letters 8: 35-42.

Laland KN, Odling-Smee FJ, Feldman MW (2001) Cultural niche construction and human evolution. Journal of Evolution Biology 14:22-33.

Lins Neto EMF, Peroni N, Casas A, Parra F, Aguirre X, Guillén S, Albuquerque UP (2014) Brazilian and Mexican experiences in the study of incipient domestication. Journal of Ethnobiology and Ethnomedicine 10(33):1-12.

MacArthur R, Pianka E (1966) On optimal use of a patchy environment. American Naturalist 100:603-609.

Molenhoff KA, Codding B (2017) When does it pay to invest in a patch? The evolution of intentional niche construction. Evolutionary Anthopology 26: 218-227.

Molenhoff KA, Brenner Coltrain J, Codding B (2015) Optimal foraging theory and nicheconstruction theory do not stand in opposition. Proceedings of the National Academy of Sciences of the United States of America 112(24):E3093.

Smith BD (2015) A comparison of niche construction theory and diet breadth models as frameworks of explanation for the initial domestication of plants and animals. Journal of Archaeology Resource 23(3):215-262.

Smith BD (2012) A Cultural Niche Construction Theory of Initial Domestication. Biology Theory 6:260-271.

Smith BD (2016) Neo-Darwinism, niche construction theory, and the initial domestication of plants and animal. Evolutionary Ecology 30(2):307-324.

Zeder MA (2015a) Core questions in domestication research. Proceedings of the National Academy of Sciences of the United States of America 112(11):3191-3198. 
Zeder MA (2015b) Reply to Molenhoff et al.: Zeder MA (2016) Domestication as a model Human behavioral ecology needs a rethink system for niche construction theory. that nicheconstruction theory can provide. Evolutionary Ecology 30:325-348.

Proceedings of the National Academy of Sciences of the United States of America 112(24): E3094. 